\title{
Performance Evaluation of Q690 High-Strength Concrete-Filled Thin-Walled Steel Tubular Columns under Compression-Bending Coupling
}

\author{
Jiantao Wang $(\mathbb{D})$ and Qing Sun (i) \\ Department of Civil Engineering, Xi'an Jiaotong University, Xi'an, Shaanxi Province 710049, China \\ Correspondence should be addressed to Qing Sun; sunq@mail.xjtu.edu.cn
}

Received 26 December 2017; Accepted 24 May 2018; Published 2 July 2018

Academic Editor: Roman Lewandowski

Copyright (C) 2018 Jiantao Wang and Qing Sun. This is an open access article distributed under the Creative Commons Attribution License, which permits unrestricted use, distribution, and reproduction in any medium, provided the original work is properly cited.

\begin{abstract}
The high-strength concrete-filled thin-walled steel tubular (HCFTST) columns, as a relatively new type structure member, could reduce the section size to obtain the favorable architecture aesthetic effects and gain further economic benefits. In this paper, the HCFTST columns were optimized on the basis of the orthogonal array of $L_{16}\left(4^{5}\right)$ with three tested parameters. The orthogonal range analysis (ORA) was utilized to research the alteration degree, and the orthogonal variance analysis (OVA) was employed to analyze the significant degree between different parameters. Moreover, the optimized combinations based on performance index including strength, ductility, and energy dissipation were recommended to offer certain reference for structural design and application. Finally, a modified damage assessment model was proposed and verified. It indicates that the HCFTST columns with reasonable design could display favorable performance and can be expected to have a widespread application in engineering structures.
\end{abstract}

\section{Introduction}

The high-strength concrete-filled thin-walled steel tubular (HCFTST) columns, as a relatively new type structure member, developed rapidly due to the use of high-strength (HS) materials. Compared to the conventional concrete-filled steel tubular (CFST) columns, it could reduce the section size to obtain the favorable architecture aesthetic effects and gain further economic benefits. For example, the fat columns in underground parking lots and libraries could be optimized to obtain the commodious building space, and the hydrogeological changes and sludge accumulation caused by the high water resistance rate of large bridge piers could also be ameliorated better by adopting HCFTST columns [13]. During the past decades, many scholars have conducted detailed researches on conventional CFST columns under compression-bending coupling loads [4-13]. For instance, Sakino and Tomii [4] revealed that the square CFST columns subjected to low-cycle loading had more obvious strength degradation with the increase of axial compression ratios, but the strength of all tested columns tended to be stable after transition period. Boyd et al. [6] studied the hysteretic performance circular CFST columns, and their research indicated that the thick steel tubes and shear connectors could improve the strength of core concrete and energy dissipation capacity of the composite columns. Marson and Bruneau [7] investigated the energy dissipation, strength, and ductility of the circular CFST columns, suggesting that the ductility of all tested columns was good, and all columns could reach the lateral drift of $7 \%$ before the significant loss in moment-bearing capacity as a result of cracks opening on the local buckles. Susantha et al. [9] performed nonlinear numerical analysis about hysteretic behavior of CFST columns and proposed a numerical model to predict the hysteretic behavior. Gajalakshmi and Helena [11] examined the cumulative damage of circular CFST columns and established a simplified equation to predict damage index. Lee [13] studied the momentcurvature formulas of high-strength concrete-filled steel square tube (HCFT) columns, and design formulas to estimate the axial load-moment-curvature were proposed based on experimental results. In addition, Elremaily and Azizinamini [14], Varma et al. [15, 16], and Skalomenos et al. [17] 

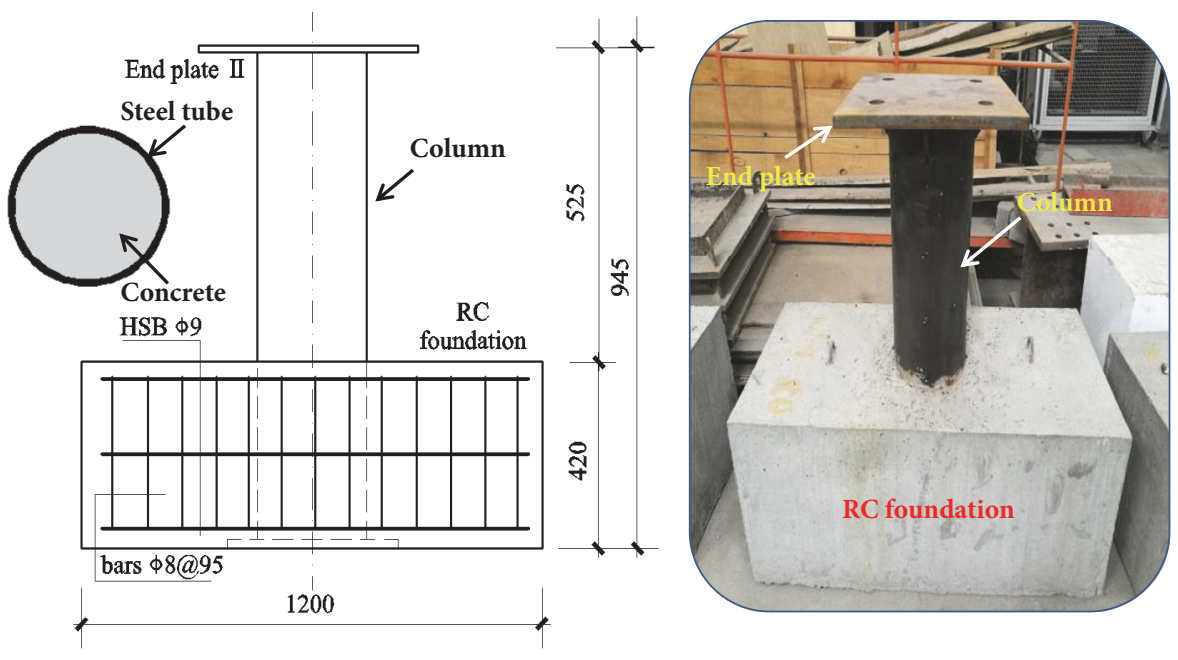

FIGURE 1: Details of test specimens.

investigated the hysteretic behavior of CFST columns using HS steel or concrete, indicating that using HS materials could promote the hysteretic behavior of CFST columns to a certain degree. Certainly, the abovementioned studies did great efforts to help understand the behavior of CFST columns under compression-bending coupling.

However, it is noteworthy that the aforementioned researches were mainly aimed at the traditional concretefilled thick-walled steel tubular columns and no HS thinwalled steel tubes were utilized in their studies. Overall, the studies about HCFTST columns were found lacking. As for the HCFTST columns, the confined effects, utilization coefficient of HS materials, and optimized collocation of HS steel and concrete under compression-bending coupling loads are different with the traditional CFST columns. The effects of diameter-to-thickness $(D / t)$ ratio, axial compression, and materials strength on performance are still uncertain. Therefore, more investigations about HCFTST columns are needed to examine the variety of mechanical property and promote the wide application.

In this paper, the HCFTST columns under compressionbending coupling were optimized on the basis of the orthogonal array of $L_{16}\left(4^{5}\right)$ with three tested parameters. The orthogonal analysis was utilized to research the alteration degree and the significant degree between different parameters. The detailed analysis including bearing capacity, ductility, and energy dissipation capacity was discussed. Moreover, the optimized combinations based on performance index were recommended to offer basic references. Finally, a modified damage assessment model was proposed and verified, which can be applied in performance evaluation of HCFTST columns.

\section{Experimental Design}

2.1. Specimen Design. Orthogonal experimental design (OED) $[18,19]$ is a method to examine the influence of multiple parameters and varied levels on the specific performance, which selects test examples from comprehensive test based on the orthogonality. Compared to disadvantages of traditional comprehensive test, OED is an efficient, fast, and economical test method [20, 21]. The test parameters including diameter-to-thickness $(D / t)$ ratio, concrete cylinder compressive strength $\left(f_{c}\right)$, and axial compression ratio $(n)$ were determined through OED to investigate the effects on performance. Q690 HS steel (yield strength $f_{y} \geq 690 \mathrm{MPa}$ ), HS concrete (cylinder compression strength $f_{c} \geq 60 \mathrm{MPa}$ ), and common-strength (CS) concrete $\left(f_{c}<60 \mathrm{MPa}\right)$ were designed in this study. A summary of the specimens is shown in Table 1 . The axial compression ratio ( $n$ ) was defined by $n=P / P_{0}$, where $P$ is the axial load applied on the HCFTST columns and $P_{0}$ is the nominal squash load calculated by $P_{0}=A_{s} f_{y}+0.85 A_{c} f_{c}$, where $A_{s}$ and $A_{c}$ are the cross-sectional areas of steel tube and core concrete, respectively [16].

The design details of all aforementioned specimens are shown in Figure 1. The height of the HCFTST columns was $525 \mathrm{~mm}$, and a reinforced concrete (RC) foundation was built for the convenience of applying cyclic loads. The cross section sizes of the RC foundation were $1200 \times 450 \times 420$ $\mathrm{mm}$ (length $\times$ width $\times$ height) and $1200 \times 500 \times 420 \mathrm{~mm}$, where the former was adopted by the HCFTST columns with diameters $140 \mathrm{~mm}$ and $180 \mathrm{~mm}$ and the latter was applied to the other specimens. HS steel bars were used to prevent the $\mathrm{RC}$ foundations from failure during test.

2.2. Test Procedure. The loading apparatus adopted for the test shown in Figure 2(a) enables the application of the constant axial compressive load combining cyclic lateral load. The axial force was applied by the hydraulic jack. The MTS 244.51 actuator was used to apply cyclic lateral load. The lateral force and displacement were monitored by the transducers of the actuator. During the test, preloading procedure was conducted to ensure the equipment ran normally. If all was in order, the axial load was applied firstly to the targeted value and then kept constant during testing. Afterwards the lateral force was cycled under the displacement control mode as shown in Figure 2(b). 


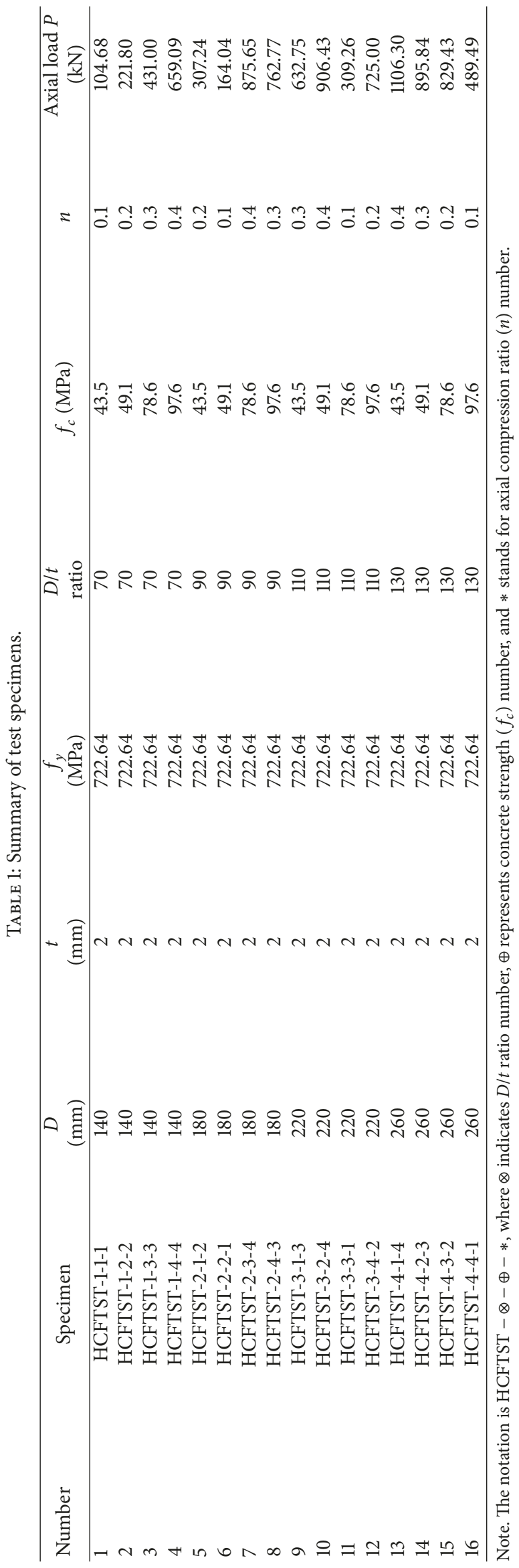




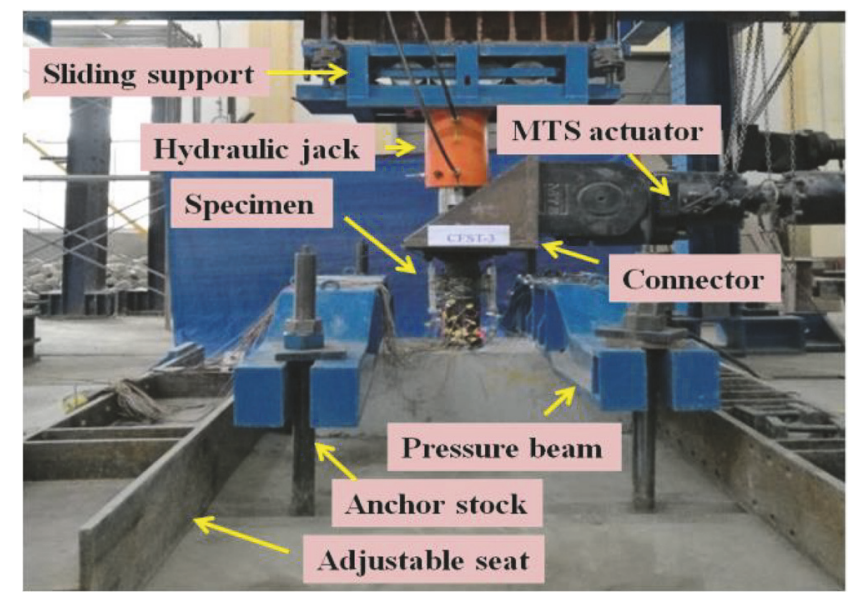

(a) Test setup

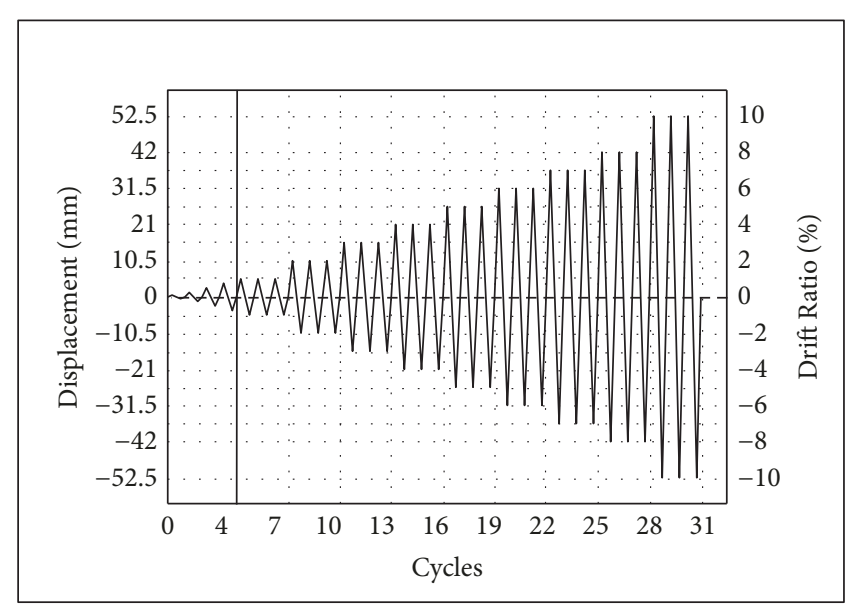

(b) Cyclic loading procedure

FIGURE 2: Test program.

\section{Orthogonal Analysis Based on Performance}

In this paper, the orthogonal analysis was adopted to investigate effects on the performance indices under the altered levels of different parameters aforementioned [19-21]. Firstly, the orthogonal range analysis (ORA) was utilized to examine the alteration degree of a specific parameter and the orthogonal variance analysis (OVA) was also employed to analyze the significant degree between different parameters. Finally, the optimized combinations based on seismic performance index including strength, ductility, and energy dissipation were recommended to offer certain reference for structural design and application.

3.1. Orthogonal Range Analysis. After the test, the lateral load-displacement hysteretic curves of all specimens could be obtained. Taking specimen HCFTST-2-3-4 as an example, Figure 3(a) shows the hysteretic curve, in which the local buckling and steel fracture were marked. The skeleton curves were constructed by connecting maximum load point at each displacement level according to the hysteretic curve, and the general yield moment (GYM) method was used to obtain the yield point $\left(\Delta y, \mathrm{P}_{\mathrm{y}}\right)$ in Figure $3(\mathrm{~b})$. Besides, the ultimate failure point is defined as $\left(\Delta \mathrm{u}, \mathrm{P}_{\mathrm{u}}\right)$, where $\Delta \mathrm{u}$ is the displacement when the load decreases to $\mathrm{P}_{\mathrm{u}}=0.85 \mathrm{P}_{\mathrm{m}}$. The peak point is $\left(\Delta \mathrm{m}, \mathrm{P}_{\mathrm{m}}\right)$. Further, the energy dissipation shown in Figure 3(c) was conducted through area integral based on the hysteretic loops. The ductility could be calculated by $\mathrm{u}=\Delta \mathrm{u} / \Delta \mathrm{y}$. Then the ORA could be conducted based on the aforementioned results. The procedure of ORA can be obtained by

$$
\begin{aligned}
& R_{P}^{j}=\max \left\{S_{j}^{1}, S_{j}^{2} \cdots S_{j}^{i}\right\}-\min \left\{S_{j}^{1}, S_{j}^{2} \cdots S_{j}^{i}\right\} \\
& S_{j}^{i}=\sum \frac{T_{j}^{i}}{k_{j}}
\end{aligned}
$$

where $R_{P}^{j}$ is the range of the $j$ th parameter, $S_{j}^{i}$ is the average index value of the $i$ th level at $j$ th parameter, $\mathrm{T}_{\mathrm{j}}^{\mathrm{i}}$ is the tested indices values of $i$ th level of $j$ th parameter, and $\mathrm{k}_{\mathrm{j}}$ is the level number of $j$ th parameter.

The ORA based on strength is shown in Figure 4, in which the parameter $D / t$ ratio has the maximum range indicating that the bearing capacity of HCFTST columns varies mostly with the increasing $D / t$ from 70 to 130 . On the other hand, improving $D / t$ when keeping wall thickness of steel tube constant, namely, enhancing cross section, can promote bearing capacity directly. For concrete strength and axial compression ratio, though a drop occurs after the third level, there is still slow growth of mean values on the whole. The asymmetric damage propagation develops obviously resulting in the degradation of negative direction for parameter $f_{c}$ and $n$ due to fragility of HS concrete and loss of confined constraint effect under thin-walled condition as shown in Figure 4.

As for the analysis of ductility index shown in Figure 5, it indicates that the ductility decreases with the increase of the $D / t$ ratio in general due to the shear cracks easily expanding under larger $D / t$ ratio. Although the discrepant fluctuation exists in positive and negative direction, for the mean ductility, using HS concrete $\left(f_{c} \geq 78.6 \mathrm{MPa}\right)$ could enhance the ductility more than CS concrete evidently. What is more, the ductility fluctuates significantly within the tested axial compression ratio. It is because that enhancement of axial load makes the HS material produce evident deformation, which can work together better with core concrete to improve the seismic behavior due to the ameliorating brittleness of HS concrete and attenuating local buckling of thin-walled steel tube.

The ORA result based on ultimate energy dissipation can be observed in Figure 6, in which concrete strength has little influence on the ultimate energy dissipation compared with the $D / t$ ratio and axial compression ratio. Improving the $D / t$ ratio can significantly promote the ultimate energy dissipation with augmenting volume under constant energy dissipation density. Besides, due to the increasing axial compression ratio, the ductility and confined effect get promoted; 


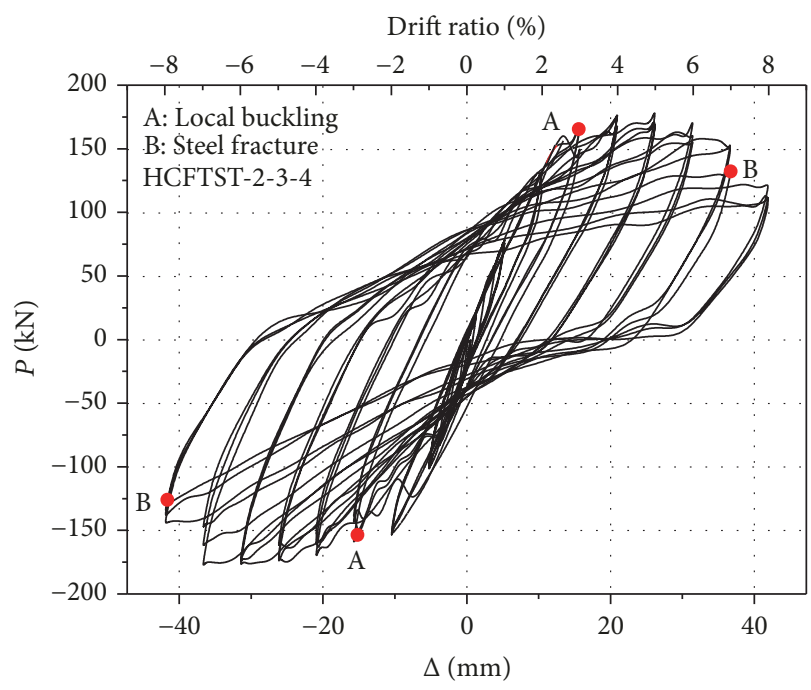

(a) Hysteretic curve

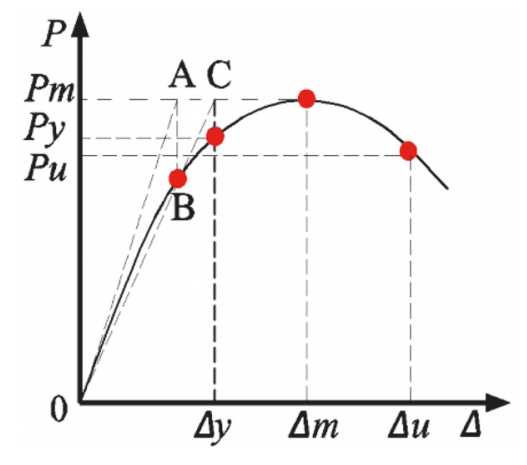

(b) GYM method

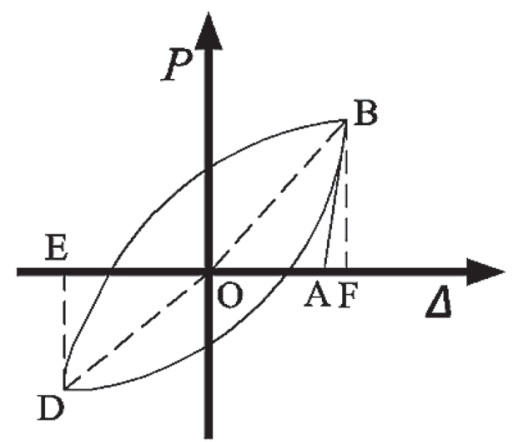

(c) Energy dissipation

FIGURE 3: Determination of performance indices.

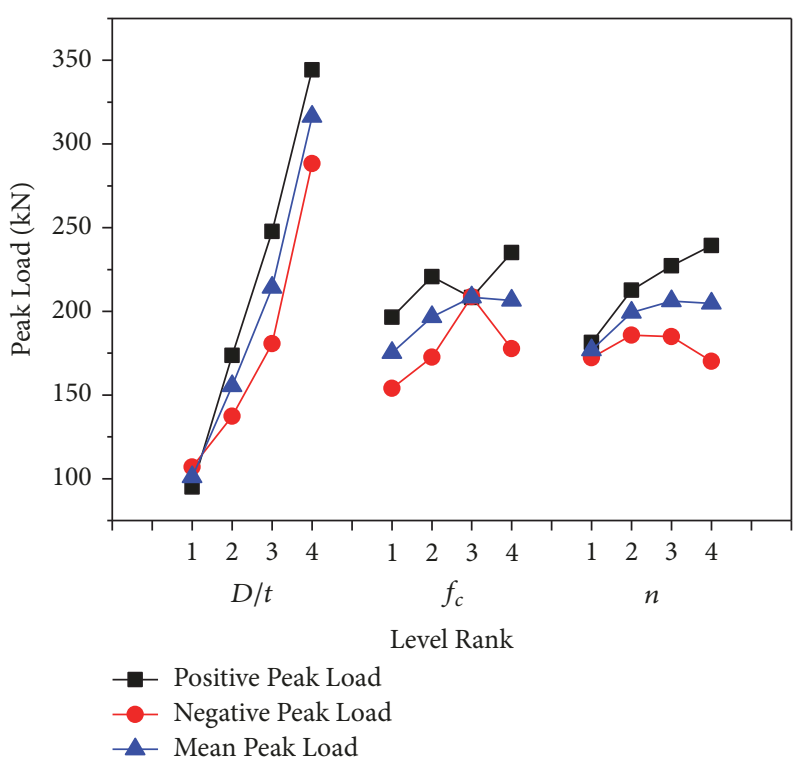

(a) Peak load analysis

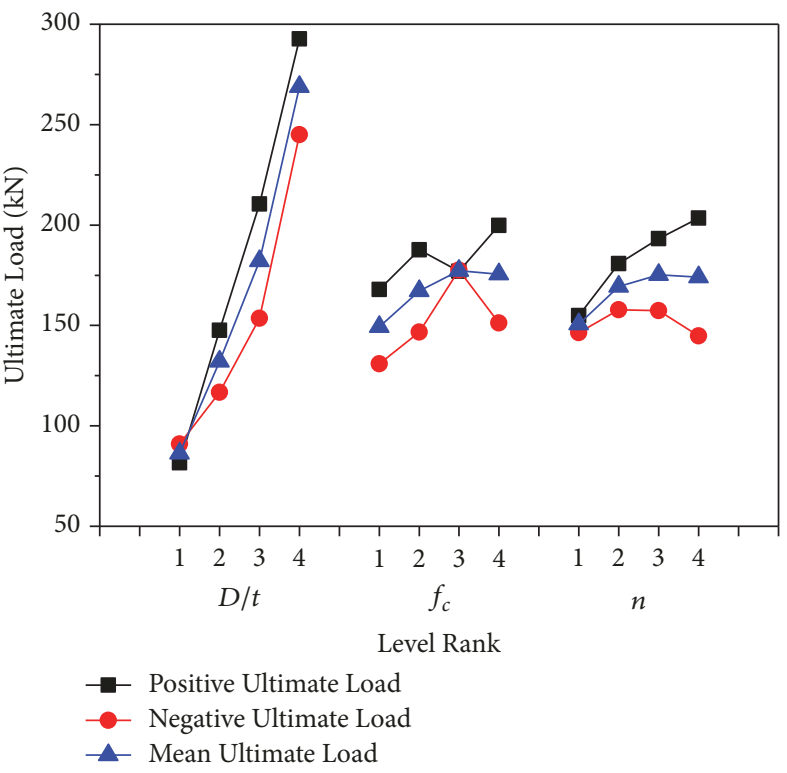

(b) Ultimate load analysis

FIgURE 4: ORA based on strength. 


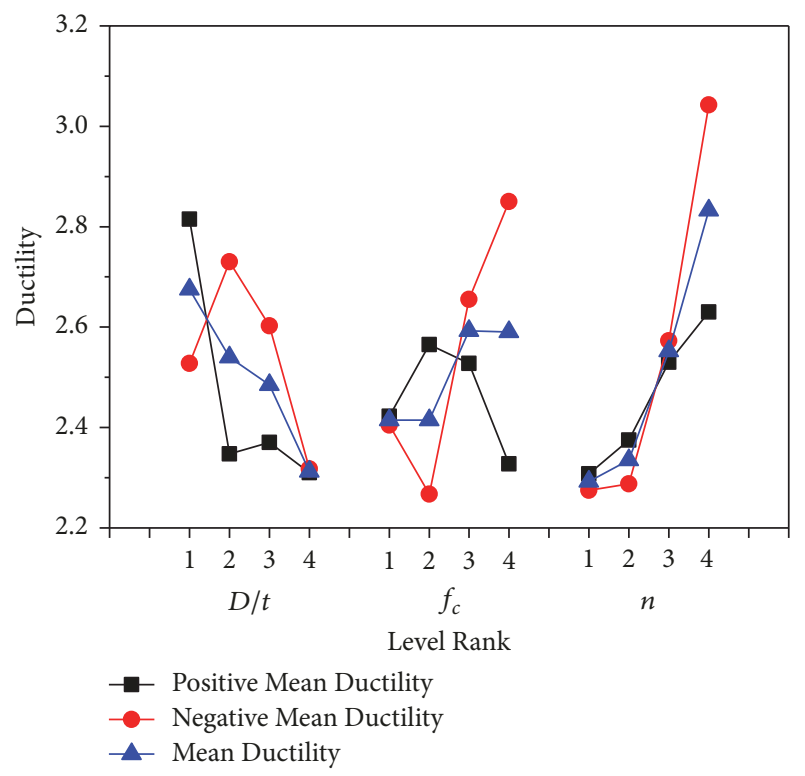

FIGURE 5: ORA based on ductility.

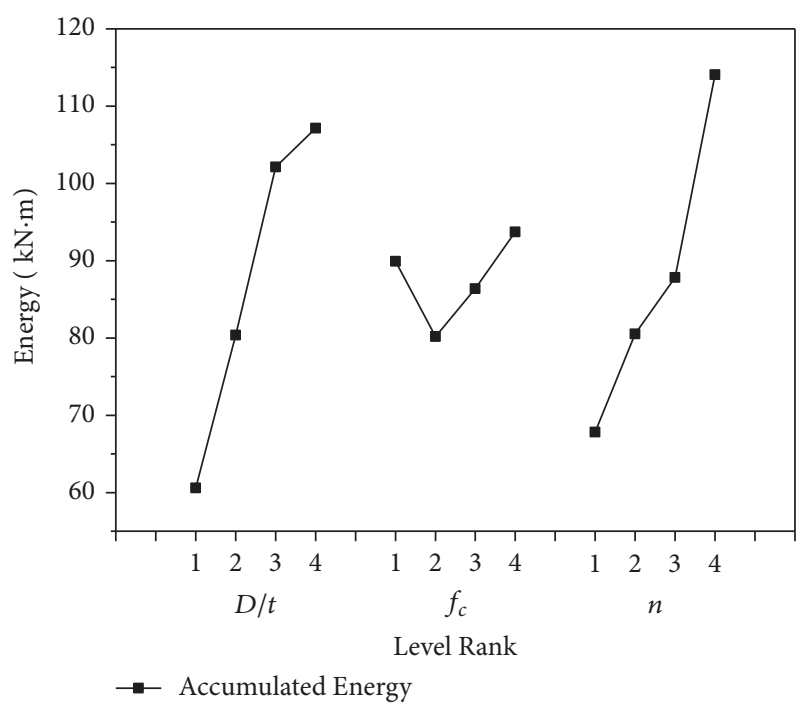

FIgURE 6: ORA based on energy dissipation.

as a result more dissipated energy is needed to reach the same deformation under cyclic loading.

3.2. Orthogonal Variance Analysis. The ORA cannot distinguish the data fluctuation caused by the level variation of different parameters with the test error; therefore it is vital to conduct significance test using OVA to examine whether the impact of each parameter on the tested performance indices is significant at specified significance degree or not based on the mathematical statistics and probability theory.

Figure 7 shows the procedure of OVA in detail, in which $\mathrm{T}_{\mathrm{A}}$ is the average value of specific performance index; $n$ is the total test number; $f_{e}$ is the freedom of test error; $f_{j}$ is the freedom of $j$ th parameter; and $V_{j}, V_{T}$, and $V_{e}$ are the

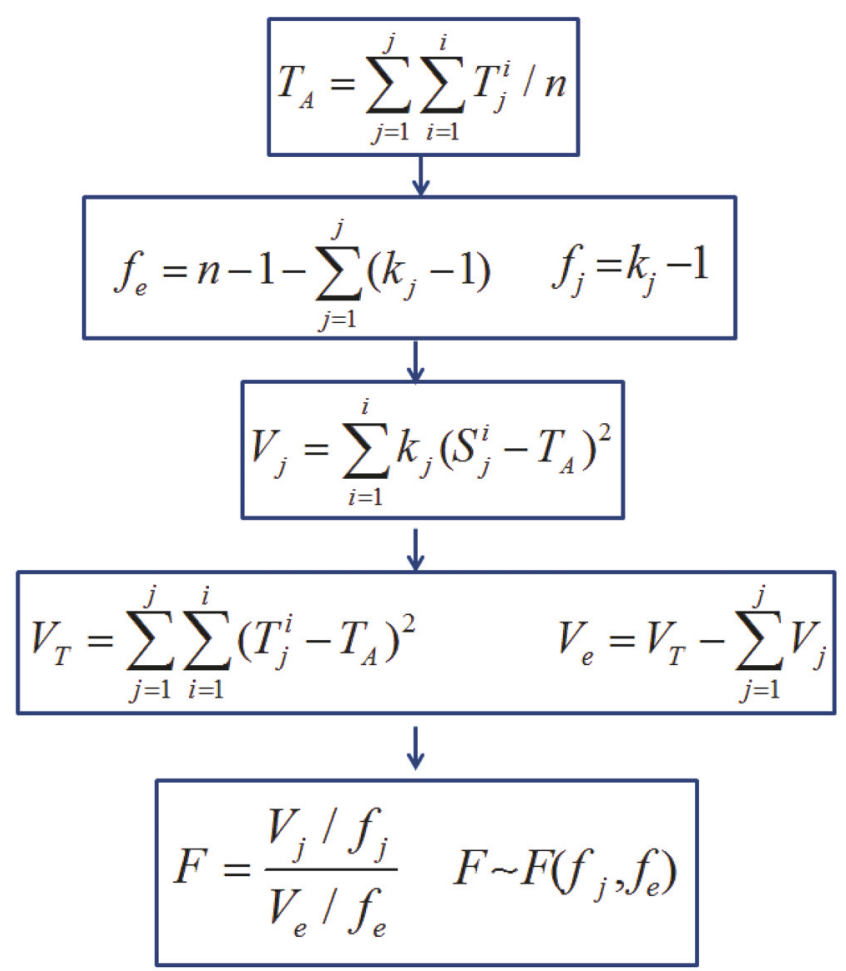

Figure 7: Procedure of OVA.

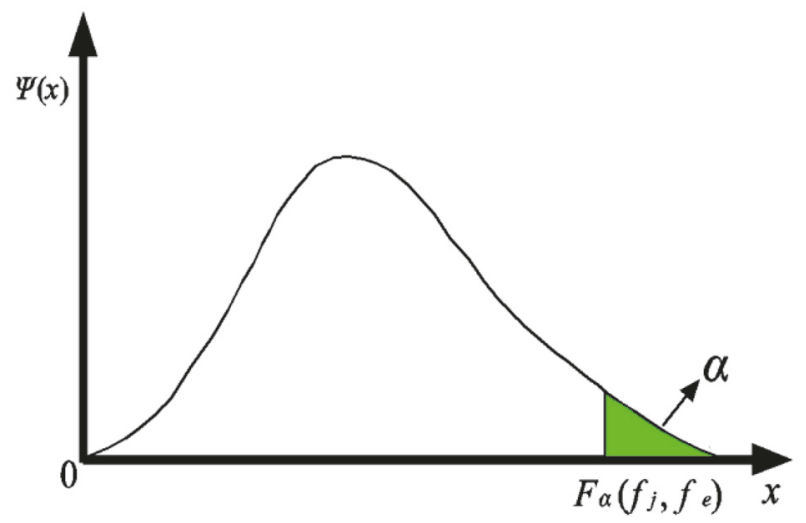

FIgURE 8: F-distribution.

variance of $j$ th parameter, total variance, and error variance, respectively. As is shown in Figure 8, the final $\mathrm{F}$ is the random variable for significance test, which submits to the $F$-distribution marked as $\mathrm{F} \sim \mathrm{F}\left(\mathrm{f}_{\mathrm{j}}, \mathrm{f}_{\mathrm{e}}\right)$. The probability density function of $F$-distribution is expressed as follows:

$$
\psi(x)=\frac{\Gamma\left[\left(f_{j}+f_{e}\right) / 2\right]\left(f_{j} / f_{e}\right)^{f_{j} / 2} x^{\left(f_{j} / 2\right)-1}}{\Gamma\left(f_{j} / 2\right) \Gamma\left(f_{e} / 2\right)\left[1+\left(f_{j} \cdot x / f_{e}\right)\right]^{\left(f_{j}+f_{e}\right) / 2}},
$$

$$
\mathrm{x}>0
$$

$\Gamma(\mathrm{x})=2 \int_{0}^{+\infty} \mathrm{t}^{2 \mathrm{x}-1} \mathrm{e}^{-\mathrm{t}^{2}} \mathrm{dt}$ 


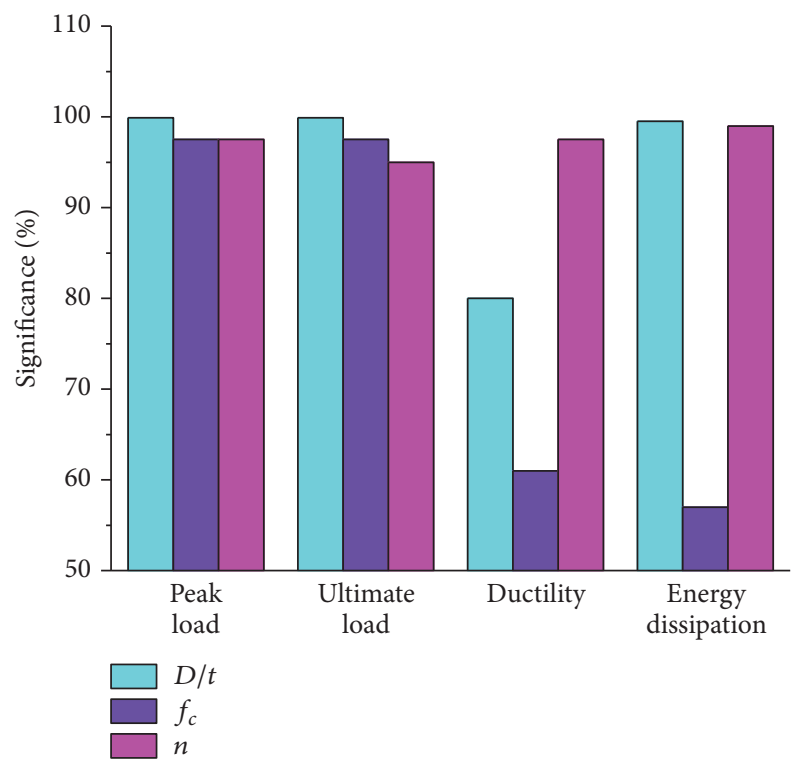

Figure 9: Significance test.

In general, the following equation can be utilized to judge the significant degree:

$$
\mathrm{P}\left\{\mathrm{F}>\mathrm{F}_{\alpha}\left(\mathrm{f}_{\mathrm{j}}, \mathrm{f}_{\mathrm{e}}\right)\right\}=\int_{\mathrm{F}_{\alpha}\left(\mathrm{f}_{\mathrm{j}}, \mathrm{f}_{\mathrm{e}}\right)}^{\infty} \psi(\mathrm{x}) \mathrm{dx}=\alpha
$$

where $\alpha$ is the confidence level. When the variable $\mathrm{F}$ satisfies the equation $\mathrm{F}>\mathrm{F}_{\alpha}\left(\mathrm{f}_{\mathrm{f}}, \mathrm{f}_{\mathrm{e}}\right)$, then there is a probability of $1-\alpha$ accepting the impacts on tested performance indices of certain parameters.

From Figure 9, it can be drawn that the tested parameters in this paper have larger significant impacts on the strength index including peak load and ultimate load; besides, the $D / t$ ratio and axial compression ratio display more obvious significance on the ductility and energy dissipation than concrete strength. Moreover, for Q690 HCFTST columns it is fatal to realize the fact that only increasing the concrete strength can slightly influence ameliorating ductility and promoting energy dissipation capacity, so the reasonable alternative type is to conduct optimized collocation considering the strength, ductility, and energy dissipation comprehensively.

3.3. Optimized Combination. In this section the optimized combinations for better performance were recommended based on the ORA and OVA aforementioned. First of all, the ranges of fluctuation for each performance index were ranked in descending order by the tested parameters as shown in Table 2. The numbers in Table 2 are the level numbers of tested parameters according to Table 1 . The underlines of the ranking indicate that both varied levels are equivalent by ignoring the test errors among $2 \%$. For a certain performance, the principle for optimized combination is that if one level under a specified parameter for the vested performance index has the lowest ranking, then the effect on the performance of this level should not be considered preferentially. Furthermore,
TABLE 2: Levels ranking.

\begin{tabular}{lccc}
\hline Parameter & Strength & Ductility & Energy dissipation capacity \\
\hline$D / t$ & $4-3-2-1$ & $1-2-3-4$ & $4-3-2-1$ \\
$f_{c}$ & $\underline{3 / 4}-2-1$ & $\underline{3 / 4}-2-1$ & $4-1-3-2$ \\
$n$ & $\underline{3 / 4}-2-1$ & $4-3-2 / 1$ & $4-3-2-1$ \\
\hline
\end{tabular}

based on results of OVA, the levels having higher ranking of superior significant parameters should be preferred at first.

Compared to OED method in this paper, there will be sixty-four specimens needed when using the comprehensive experimental method under the condition of three parameters and four levels. Therefore the optimized combination based on performance including strength, ductility, and energy dissipation should be utilized to evaluate the tested specimens and offer four optimized combinations for each series of HCFTST columns among sixty-four potential combinations of comprehensive test. The evaluation ranking based on the overall performance can be seen for each series, and optimized combinations using HS materials are recommended in Table 3. Obviously, for different $D / t$ ratios the specimens using HS materials could achieve the best optimized comprehensive behavior under higher axial compression ratio within test scope, which also indicates that the CFST columns using HS core concrete restrained by HS thin-walled steel tube could exhibit their potential advantages under higher axial compression level than CFST columns using CS materials.

\section{Damage Assessment Model}

In design of HCFTST columns, it is generally necessary to carry out damage assessment. The single parameter damage model was often used to estimate the damage degree. However, a large deviation when adopting different damage parameters would occur. Figure 10 depicts the different damage tendency based on stiffness degradation and energy dissipation, respectively. To overcome the disadvantage above, double parameter Park-Ang damage model was proposed to balance the deviation [22]. It should be noted that the model was used for the damage assessment of reinforced concrete structures and cannot be applied to HCFTST columns directly, because the mechanical property is completely different between two structures. Therefore, Wu et al. [23] proposed a double parameter damage model of conventional CFST columns to conduct damage-based design based on the Park-Ang model. In this paper, a modified double parameter damage model based on stiffness degradation and dissipated energy was established to estimate the damage of HCFTST columns. The asymmetric energy dissipation was taken into consideration [24]. The modified model is as follows:

$$
D_{c d}=\frac{K_{0}-K_{i}}{K_{0}}+\beta \cdot\left(\frac{E_{i}}{E_{t}}+\frac{\left|E_{P i}-E_{N i}\right|}{E_{t}}\right) \cdot \frac{K_{i}}{K_{0}}
$$

where $\mathrm{D}_{\mathrm{cd}}$ is the cumulative damage value; $\mathrm{K}_{0}$ is initial tangent stiffness and $\mathrm{K}_{\mathrm{i}}$ is the residual stiffness at $i$ th deformation level; $\mathrm{E}_{\mathrm{t}}$ and $\mathrm{E}_{\mathrm{i}}$ are monotonous ultimate dissipated 
TABLE 3: Evaluation and optimized combination results.

\begin{tabular}{|c|c|c|}
\hline $\begin{array}{l}\text { Specimen } \\
\text { series }\end{array}$ & Evaluation ranking & $\begin{array}{l}\text { Optimized } \\
\text { combinations } \\
\text { recommended }\end{array}$ \\
\hline HCFTST-1 & HCFTST-1-4-4>HCFTST-1-3-3>HCFTST-1-2-2>HCFTST-1-1-1 & HCFTST-1-4-4 \\
\hline HCFTST-2 & HCFTST-2-4-3>HCFTST-2-3-4>HCFTST-2-1-2>HCFTST-2-2-1 & $\begin{array}{c}\text { HCFTST-2-4- } \\
4 *\end{array}$ \\
\hline HCFTST-3 & HCFTST-3-4-2>HCFTST-3-2-4>HCFTST-3-1-3>HCFTST-3-3-1 & $\begin{array}{c}\text { HCFTST-3-4- } \\
4 *\end{array}$ \\
\hline HCFTST- 4 & HCFTST-4-1-4>HCFTST-4-2-3>HCFTST-4-3-2>HCFTST-4-4-1 & $\begin{array}{c}\text { HCFTST-4-4- } \\
4 *\end{array}$ \\
\hline
\end{tabular}

Note. $*$ indicatesthe potential optimized combinations using HS material which are untested in this study.

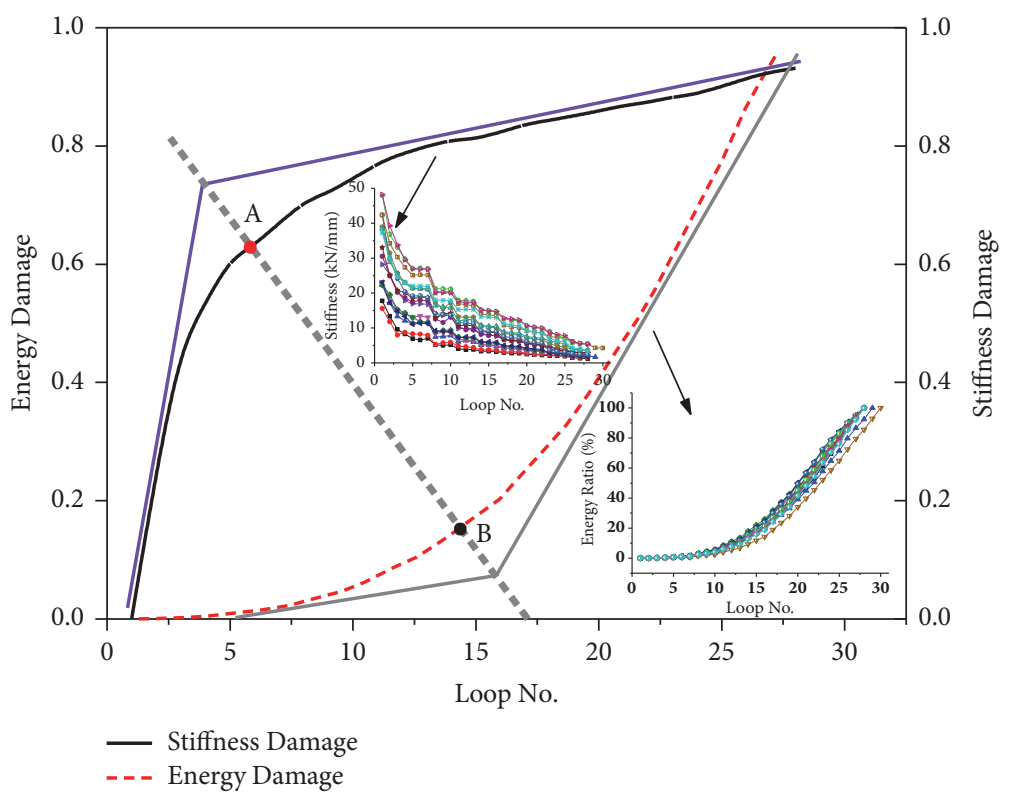

Figure 10: Conflict of different single parameter model.

energy and accumulated energy at ith drift ratio; $\mathrm{E}_{\mathrm{t}}$ could be calculated by the skeleton curve; and $\mathrm{E}_{\mathrm{Pi}}$ and $\mathrm{E}_{\mathrm{Ni}}$ are the energy dissipation of the half loop of the positive and negative direction at $i$ th deformation level. Moreover, the residual stiffness could be expressed as

$$
\frac{\mathrm{K}_{\mathrm{i}}}{\mathrm{K}_{0}}=-\ln (0.39) \cdot 0.39^{\Delta / \Delta \mathrm{m}} \text {. }
$$

As for the $\beta$, it is the dissipated energy coefficient to counterpoise the deviation between the stiffness degradation and dissipated energy, which could be derived by the final failure state $\mathrm{D}_{\mathrm{cd}}=1$ based on the data statistic:

$$
\begin{aligned}
\beta= & -0.5981+0.0045 \cdot\left(\frac{D}{t}\right)-0.0242 \xi-0.0809 n \\
& +0.1153 \cdot\left(\frac{L}{D}\right)
\end{aligned}
$$

where $\xi$ is the confined effect coefficient and can be expressed as $\xi=\mathrm{f}_{\mathrm{y}} \mathrm{A}_{\mathrm{s}} /\left(\mathrm{f}_{\mathrm{c}} \mathrm{A}_{\mathrm{c}}\right) \cdot \mathrm{A}_{\mathrm{s}}$ and $\mathrm{A}_{\mathrm{c}}$ are the cross section area of steel tube and core concrete, respectively. In contrast, the confined effect coefficient of Wu model is as follows:

$$
\begin{aligned}
\beta= & 0.045-0.042 \times \frac{\xi}{\ln (4 \mathrm{~L} / \mathrm{D})} \\
& +\frac{0.071}{1+((\mathrm{n} / \ln (4 \mathrm{~L} / \mathrm{D})-0.176) / 0.021)^{2}} .
\end{aligned}
$$

Figure 11 displayed damage assessment examples of tested specimens. Four damage development curves were presented. The first is the assessment result of the modified model in this paper; the second is the result calculated through (6) by ignoring asymmetric energy; the third curve is obtained by (6) and (9); the last curve is the damage assessment of the $\mathrm{Wu}$ model. The assessment results indicate that the damage tendency of the proposed model expands slightly larger than the second curve, which is due to the tiny asymmetric damage during symmetrical loading. The distinct dissimilarity between the first, third, and the last curve indicates that the confined effect coefficient obtained by (9) underestimates the cumulative damage degree obviously with the increasing of 


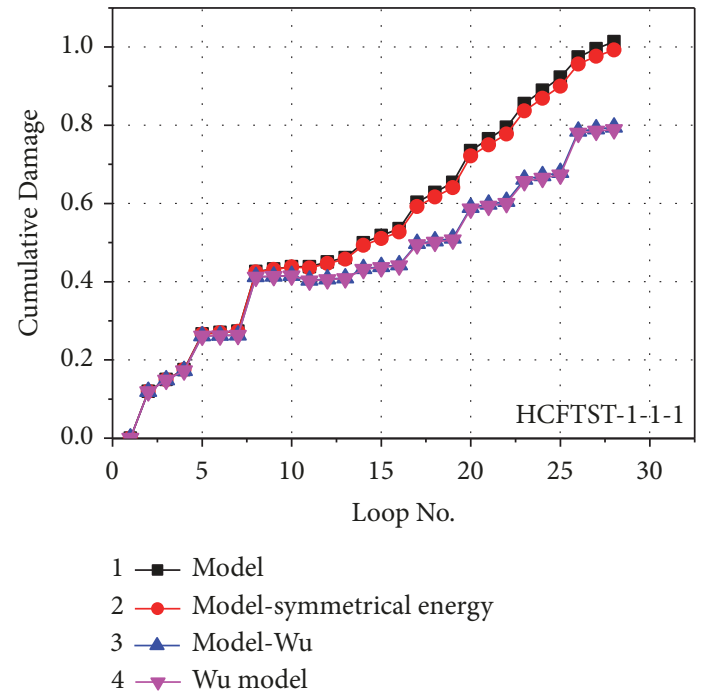

(a) HCFTST-1-1-1

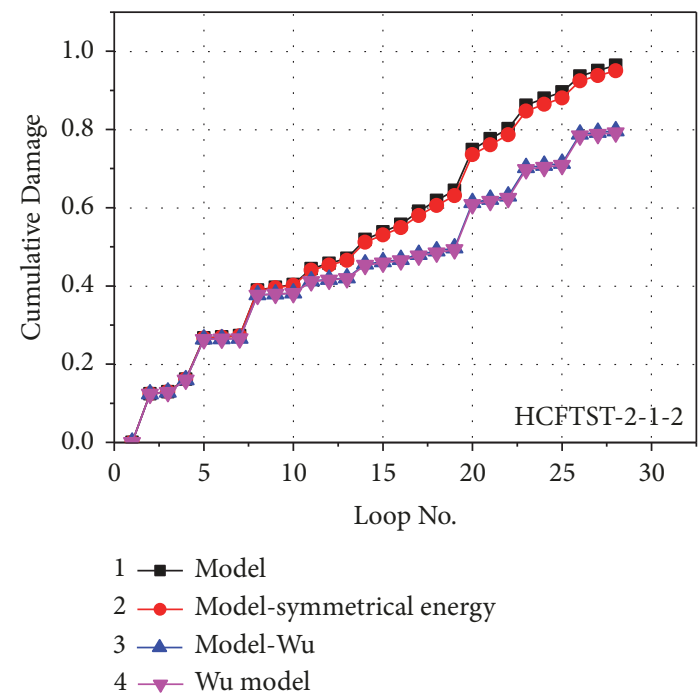

(c) HCFTST-2-1-2

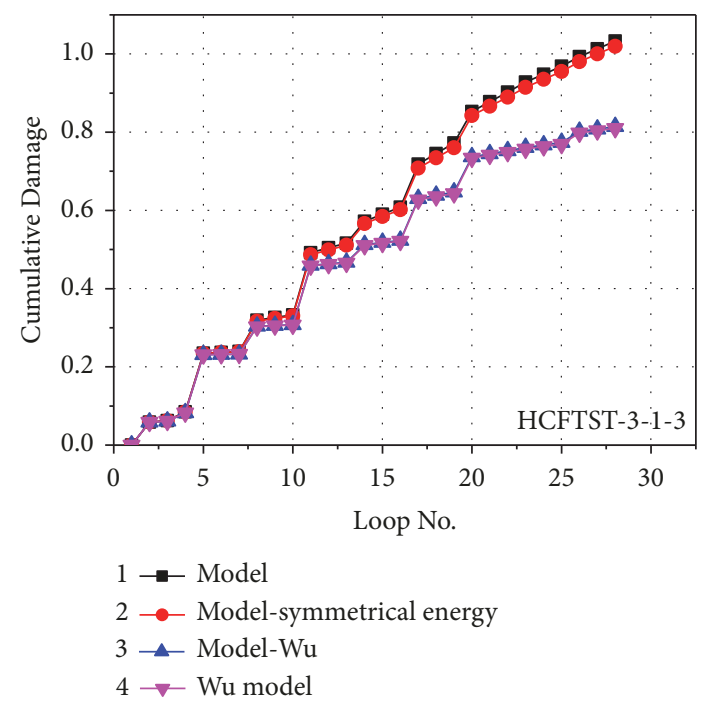

(e) HCFTST-3-1-3

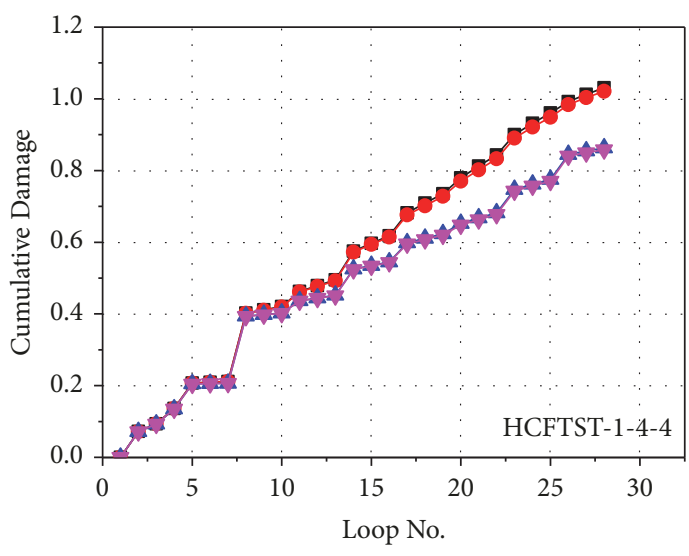

$1 \rightarrow-$ Model

2 - Model-symmetrical energy

$3 \multimap$ Model-Wu

$4 \rightarrow$ Wu model

(b) HCFTST-1-4-4

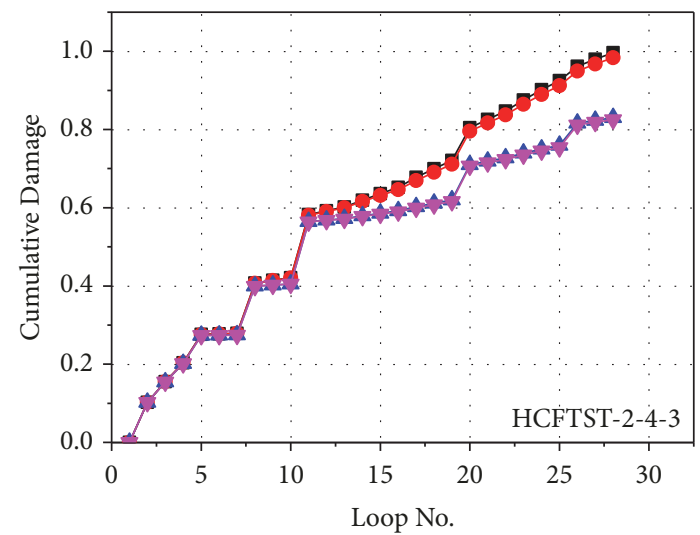

$1 \rightarrow$ Model

$2 \multimap$ Model-symmetrical energy

$3 \_$Model-Wu

$4 \rightarrow-$ Wu model

(d) HCFTST-2-4-3

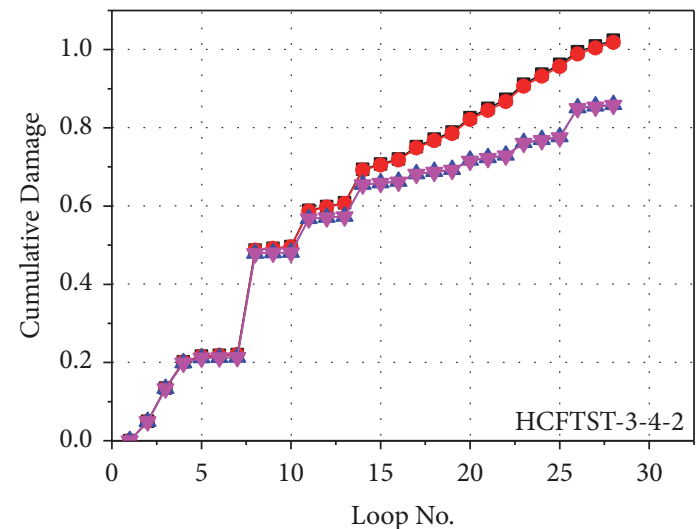

$1 \rightarrow$ Model

$2 \rightarrow$ Model-symmetrical energy

$3 \_$- Model-Wu

$4 \rightarrow-$ Wu model

(f) HCFTST-3-4-2

Figure 11: Continued. 


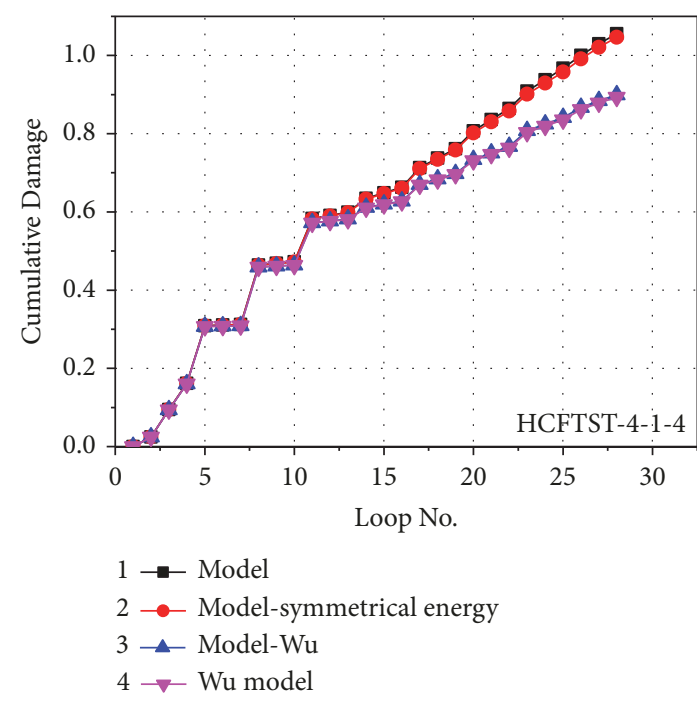

(g) HCFTST-4-1-4

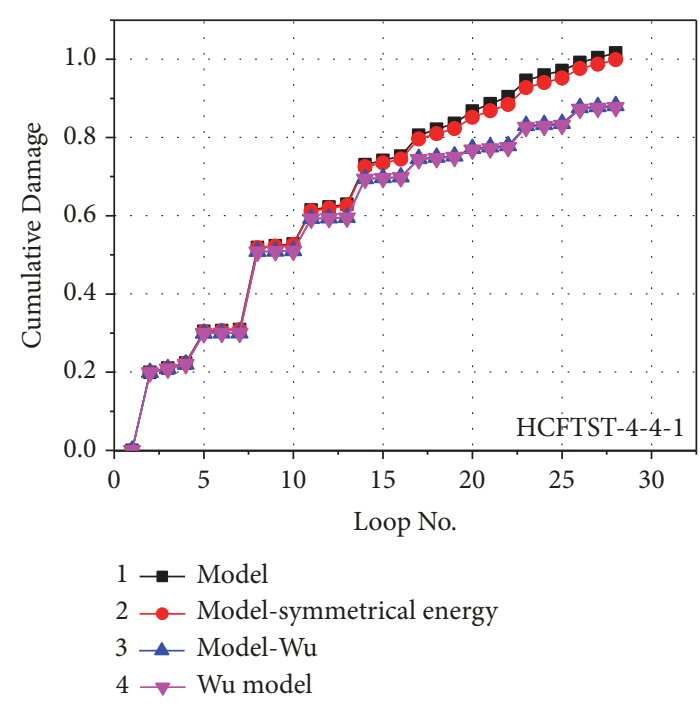

(h) HCFTST-4-4-1

FIGURE 11: Comparison of different damage assessment results.

drift ratios. The confined coefficient $(\beta)$ in (9) is actually derived from traditional CFST columns, and it often has more thicker steel tubes due to the lower steel yield strength and concrete strength under the same conditions. With continuing cyclic loading, the thick steel tubes of traditional CFST columns could offer adequate confined effects to delay the crushing of core concrete. Contrarily, the tested HCFTST columns have thin-walled HS steel tubes, so they easily promote the damage growth after the initial local buckling. Therefore, the confined coefficient $(\beta)$ of traditional CFST columns in (9) cannot reflect the true cumulative damage of HCFTST columns, especially the damage development after the local buckling of thin-walled HS steel tubes.

The damage summary of all tested specimens is shown in Figure 12, in which the damage thresholds of different performance levels were offered based on the experimental phenomena. The HCFTST columns with damage values below 0.1 are basically intact. In minor damage $(0.1<\mathrm{D} \leq$ 0.3 ) state, the columns enter into the elasto-plastic working period and the cracks develop gradually in concrete of tensile zone under the cyclic compression-bending coupling. With the emerging of initial local buckling, the HCFTST columns enter into the moderate damage $(0.3<\mathrm{D} \leq 0.6)$ accompanied by core concrete crushing. It can be observed that the cumulative damage values have a faster increase as the local buckling appears at drift ratio 2\% 3\%. The HCFTST columns can still resist the axial and cyclic lateral load ting. After the rupture of the HS thin-walled steel tubes at the drift ratios of $6 \% \sim 7 \%$, the columns are subjected to severe damage with the cumulative damage values within the scope of $0.6<$ $\mathrm{D} \leq 0.85$. When the drift ratios reach $8 \%$, the tested columns with cumulative damage values over 0.85 cannot sustain the cyclic loading and would collapse. Through the damage estimation of the HFCFTST columns, it can be concluded that the columns in minor damage period generally can continue work without mending. The columns in moderate

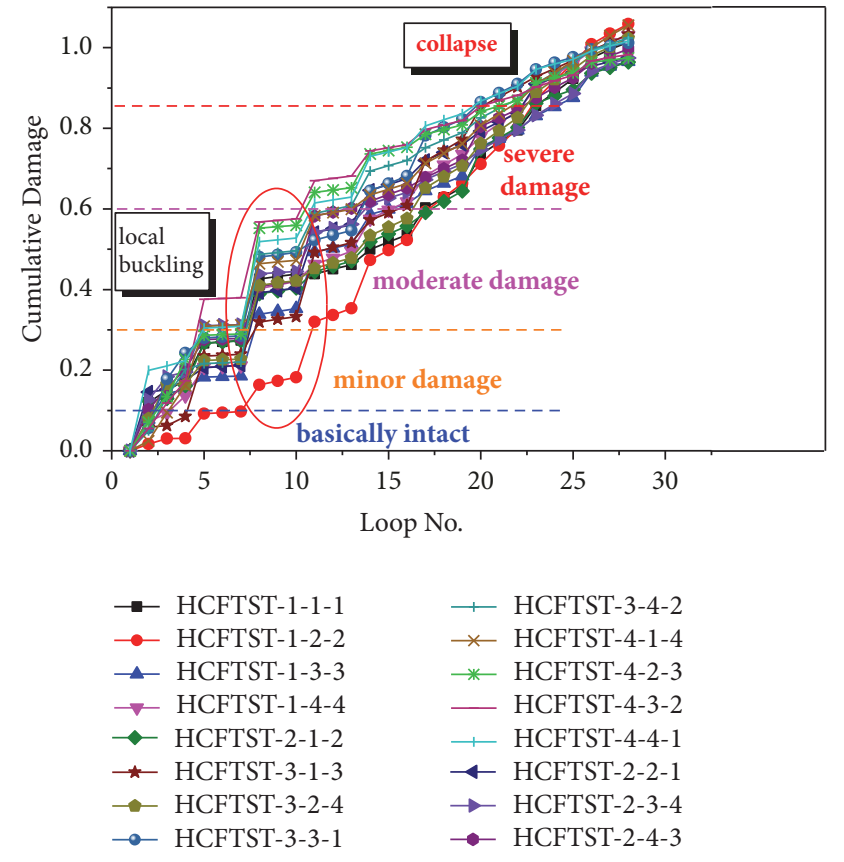

FIGURE 12: Summary of damage assessment.

damage stage need to be repaired appropriately for continued use. When in severe damage period, the columns should be repaired thoroughly or the partial components of those columns should be replaced. Further, when in collapse stage, the structures could not continue to work and should be removed thoroughly.

\section{Conclusions}

In this paper, the performance of Q690 HCFTST columns under compression-bending coupling was optimized on the 
basis of the orthogonal theory, and a modified damage assessment model was proposed. Some important conclusions could be drawn within the limited research scope:

(1) The orthogonal analysis result indicates that the tested parameters have larger significant impacts on the strength index including peak loads and ultimate loads; besides, the $D / t$ ratio and axial compression ratio display more obvious significance on the ductility and energy dissipation than concrete strength.

(2) The CFST columns using HS core concrete restrained by HS thin-walled steel tube could exhibit their potential advantages under higher axial compression level than CFST columns using CS materials. Moreover, for HCFTST columns it is fatal to realize the fact that only increasing the concrete strength can slightly influence ameliorating ductility and promoting energy dissipation capacity, so the reasonable alternative type is to conduct optimized collocation considering the strength, ductility, and energy dissipation comprehensively.

(3) A modified double parameter damage model based on stiffness degradation and dissipated energy was established to estimate the damage of Q690 HCFTST columns. The quantization of damage degree in different working condition of life cycle was conducted to provide basic references for damage-based design.

(4) The research in this paper indicates that the Q690 HCFTST columns with reasonable design could display favorable performance and can be expected to have a widespread application in engineering structures.

\section{Conflicts of Interest}

The authors declare that there are no conflicts of interest regarding the publication of this paper.

\section{Acknowledgments}

This research work was financially supported by the National Natural Science Foundation of China (Grant No. 11172226), which is gratefully acknowledged. The authors are also grateful to everyone participating in this experimental program for their selfless assistance.

\section{References}

[1] A. H. Varma, J. M. Ricles, R. Sause, and L.-W. Lu, "Seismic behavior and modeling of high-strength composite concretefilled steel tube (CFT) beam-columns," Journal of Constructional Steel Research, vol. 58, no. 5-8, pp. 725-758, 2002.

[2] F.-Y. Liao, L.-H. Han, and Z. Tao, "Behaviour of composite joints with concrete encased CFST columns under cyclic loading: experiments," Engineering Structures, vol. 59, pp. 745-764, 2014.

[3] A. H. Zubydan and A. I. Elsabbagh, "Monotonic and cyclic behavior of concrete-filled steel-tube beam-columns considering local buckling effect," Thin-Walled Structures, vol. 49, no. 4, pp. $465-481,2011$.
[4] K. Sakino and M. Tomii, "Hysteretic behavior of concrete filled square steel tubular beam-columns failed in flexure [J]," Transactions of the Japan Concrete Institute, vol. 3, no. 6, pp. 439-446, 1981.

[5] Y. Morishita and M. Tomii, "Experimental studies on bond strength between square steel tube and encased concrete core under cyclic shearing force and constant axial force [J]," Transactions of Japan Concrete Institute, vol. 4, pp. 363-370, 1982.

[6] P. F. Boyd, W. F. Cofer, and D. I. McLean, "Seismic performance of steel-encased concrete columns under flexural loading," ACI Structural Journal, vol. 92, no. 3, pp. 355-364, 1995.

[7] J. Marson and M. Bruneau, "Cyclic testing of concrete-filled circular steel bridge piers having encased fixed-based detail," Journal of Bridge Engineering, vol. 9, no. 1, pp. 14-23, 2004.

[8] H. G. L. Prion and J. Boehm, "Beam-column behavior of steel tubes filled with high strength concrete," Canadian Journal of Civil Engineering, vol. 21, no. 2, pp. 207-218, 1994.

[9] K. A. S. Susantha, H. Ge, and T. Usami, "Cyclic analysis and capacity prediction of concrete-filled steel box columns," Earthquake Engineering \& Structural Dynamics, vol. 31, no. 2, pp. 195-216, 2002.

[10] L.-H. Han and Y.-F. Yang, "Cyclic performance of concretefilled steel CHS columns under flexural loading," Journal of Constructional Steel Research, vol. 61, no. 4, pp. 423-452, 2005.

[11] P. Gajalakshmi and H. J. Helena, "Behaviour of concrete-filled steel columns subjected to lateral cyclic loading," Journal of Constructional Steel Research, vol. 75, pp. 55-63, 2012.

[12] R. Yadav, B. Chen, H. Yuan, and Z. Lian, "Analytical Behavior of CFST Bridge Piers under Cyclic Loading," in Proceedings of the 11th International Symposium on Plasticity and Impact Mechanics, IMPLAST 2016, pp. 1731-1738, ind, December 2016.

[13] S.-J. Lee, "Capacity and the moment-curvature relationship of high-strength concrete filled steel tube columns under eccentric loads," Steel and Composite Structures, vol. 7, no. 2, pp. 135-160, 2007.

[14] A. Elremaily and A. Azizinamini, "Behavior and strength of circular concrete-filled tube columns," Journal of Constructional Steel Research, vol. 58, no. 12, pp. 1567-1591, 2002.

[15] A. H. Varma, J. M. Ricles, R. Sause, and L.-W. Lu, "Experimental behavior of high strength square concrete-filled steel tube beam-columns," Journal of Structural Engineering, vol. 128, no. 3, pp. 309-318, 2002.

[16] A. H. Varma, J. M. Ricles, R. Sause, and L.-W. Lu, "Seismic behavior and design of high-strength square concrete-filled steel tube beam columns," Journal of Structural Engineering, vol. 130, no. 2, pp. 169-179, 2004.

[17] K. A. Skalomenos, K. Hayashi, R. Nishi, H. Inamasu, and M. Nakashima, "Experimental behavior of concrete-filled steel tube columns using ultrahigh-strength steel," Journal of Structural Engineering (United States), vol. 142, no. 9, 2016.

[18] S. Addelman, "Orthogonal main-effect plans for asymmetrical factorial experiments," Technometrics. A Journal of Statistics for the Physical, Chemical and Engineering Sciences, vol. 4, pp. 2146, 1962.

[19] C.-S. Cheng, "Some projection properties of orthogonal arrays," The Annals of Statistics, vol. 23, no. 4, pp. 1223-1233, 1995.

[20] A. S. Hedayat, N. J. A. Sloane, and J. Stufken, Orthogonal Arrays: Theory and Applications, Springer, New York, NY, USA, 1999.

[21] K. Ye, "Experiments: Planning, analysis, and parameter design optimization," Interfaces, vol. 33, no. 5, pp. 96-96, 2003. 
[22] Y.-J. Park and A. H.-S. Ang, "Mechanistic seismic damage model for reinforced concrete," Journal of Structural Engineering, vol. 111, no. 4, pp. 722-739, 1985.

[23] Y. Wu, Z. Huang, V. Wlee, and et al., "Stiffness degradation and hysteretic energy dissipation based damage model of concretefilled circular steel tube columns," Earthquake Engineering ¿amp; Engineering Dynamics, 2014, Stiffness degradation and hysteretic energy dissipation based damage model of concretefilled circular steel tube columns [J]. Earthquake Engineering Engineering Dynamics.

[24] S. L. McCabe and W. J. Hall, "Assessment of seismic structural damage," Journal of Structural Engineering (United States), vol. 115 , no. 9, pp. 2166-2183, 1989. 


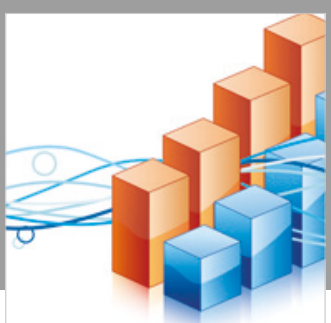

Advances in

Operations Research

\section{-n-m}
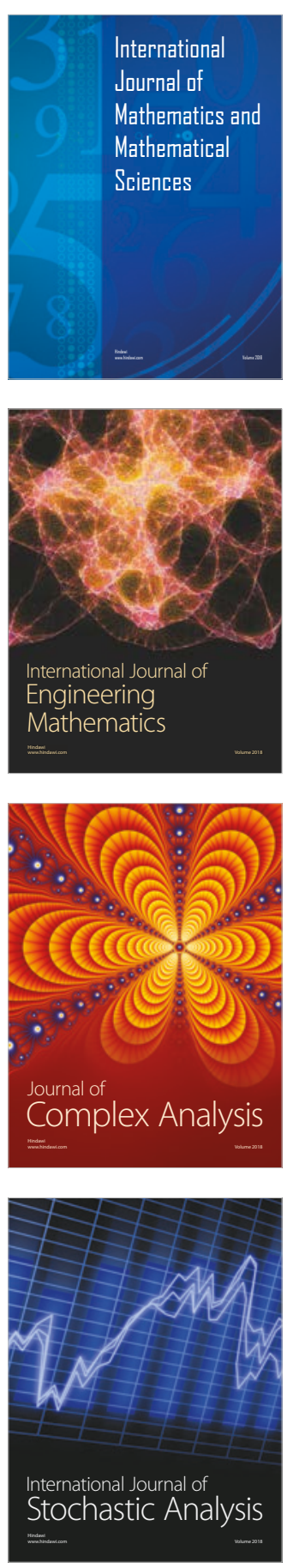
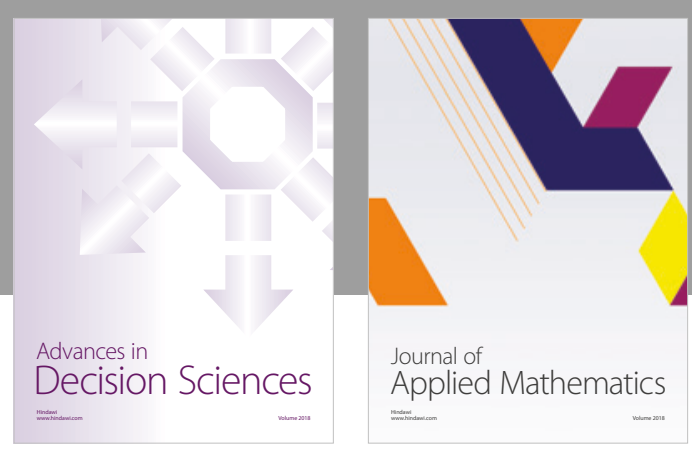

Journal of

Applied Mathematics
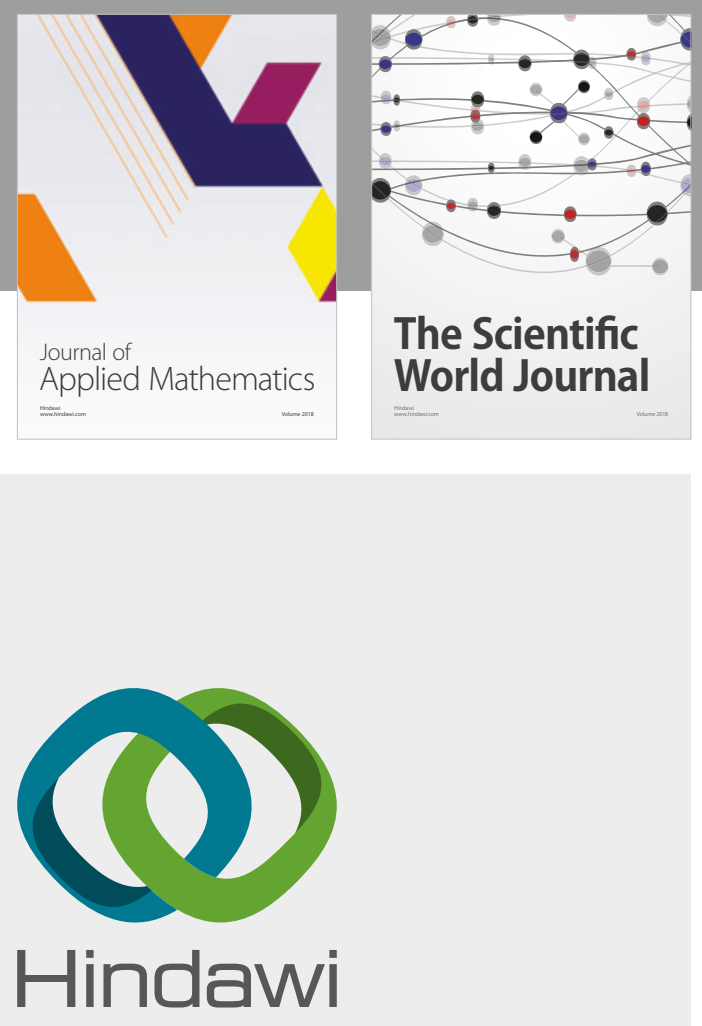

Submit your manuscripts at

www.hindawi.com

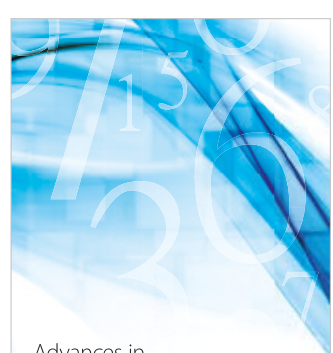

Advances in
Numerical Analysis
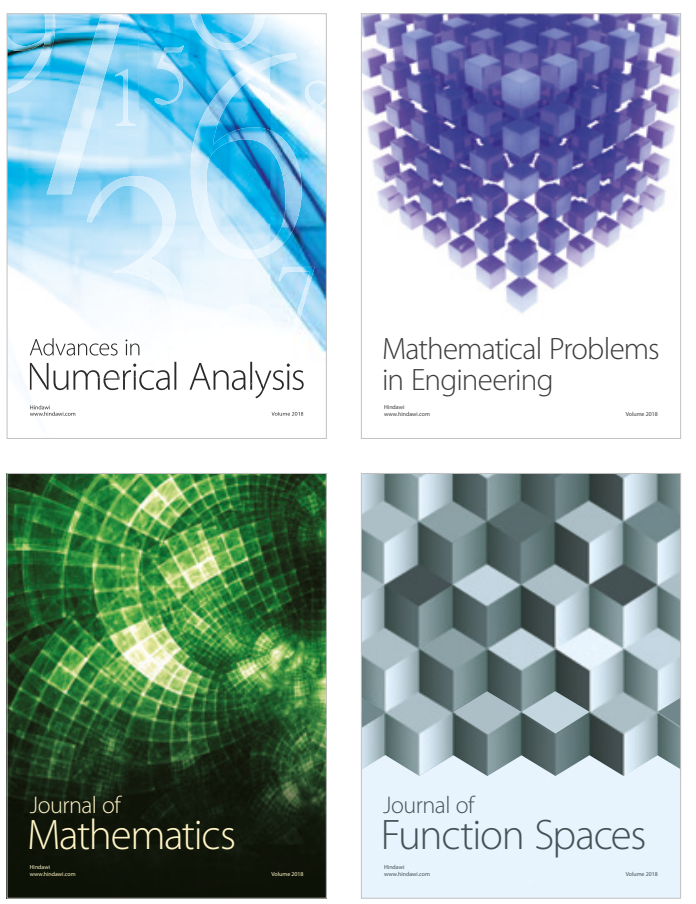

Mathematical Problems in Engineering

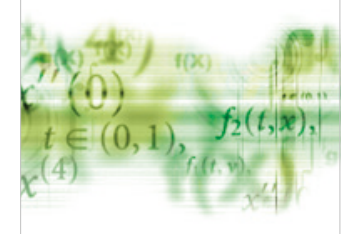

International Journal of

Differential Equations

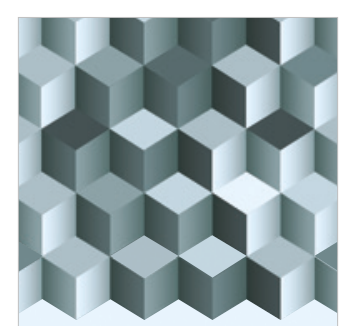

Journal of

Function Spaces

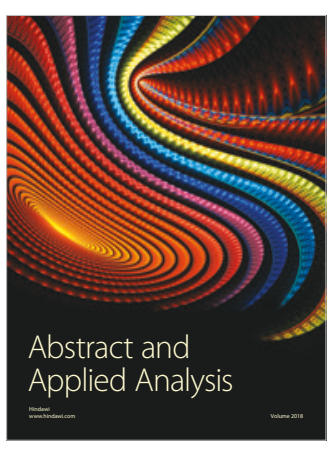

The Scientific

World Journal

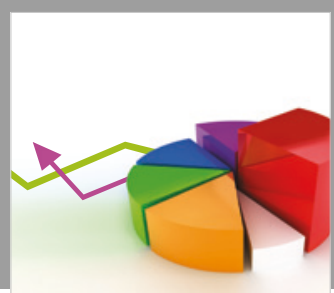

Journal of

Probability and Statistics
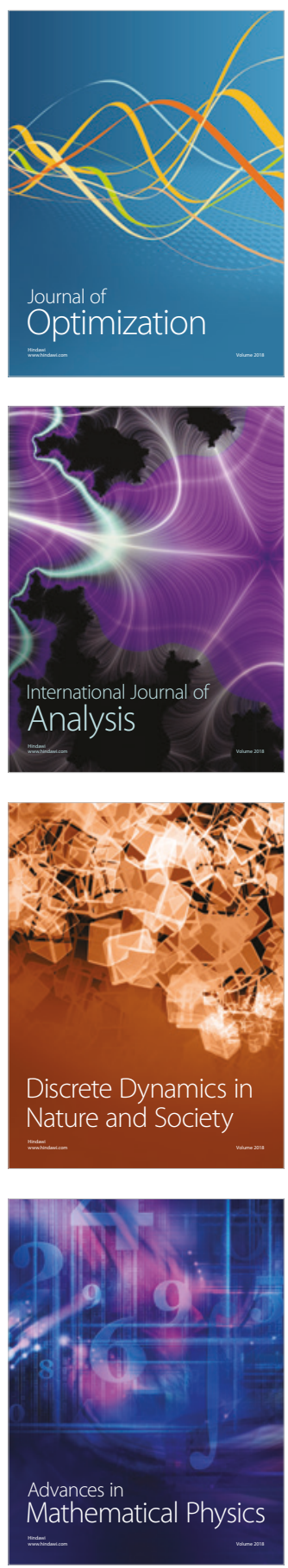